\title{
Inativação de microrganismos indicadores de contaminação fecal por radiação ultravioleta e avaliação dos fenômenos de fotorreativação e recuperação no escuro
}

Inactivation of indicator microorganisms of faecal contamination by ultraviolet radiation and evaluation of photoreactivation and dark repair phenomena

\author{
Carlos Raphael Pedroso', Jeanette Beber de Souza' ${ }^{1}$, \\ Thaís Kovalski', Carlos Magno de Sousa Vidal' ${ }^{\circledR}$, Kelly Geronazzo Martins ${ }^{1} @$
}

\begin{abstract}
RESUMO
Esta pesquisa teve como objetivo avaliar o desempenho da radiação ultravioleta (UV) para a desinfecção de efluente final de estação de tratamento de esgoto (ETE) sanitário municipal, em escala de bancada de laboratório e operação em batelada. Foram analisadas as interferências dos parâmetros operacionais tempo de exposição (s) à radiação e altura de lâmina líquida ( $\mathrm{cm}$ ) do efluente no reator UV. A eficiência do processo de desinfecção foi avaliada empregando os microrganismos indicadores Clostridium perfringens (C. perfringens), colifagos, Escherichia coli (E. coli) e coliformes totais (CT). Após a desinfecção, foram avaliados os fenômenos de recuperação microbiológica fotorreativação e recuperação no escuro para $E$. coli e $C T$. Os resultados indicaram efetiva inativação dos microrganismos indicadores à radiação UV no decorrer do tempo de exposição, o que foi comprovado estatisticamente pela ANOVA de medidas repetidas. C. perfringens foi o microrganismo que apresentou a maior resistência à inativação. Nos ensaios de recuperação microbiológica, ambos os mecanismos foram considerados insignificantes, o que foi comprovado estatisticamente pelos testes $t$ de Student (dados paramétricos) e Wilcoxon (dados não paramétricos). Em todas as análises, o nível de significância foi de 5\%. Palavras-chave: desinfecção; radiação ultravioleta; microrganismos indicadores de contaminação fecal; mecanismos de recuperação microbiológica.
\end{abstract}

\begin{abstract}
This research aimed to evaluate the performance of ultraviolet radiation (UV) for disinfecting effluents from a municipal wastewater treatment plant, in laboratory bench scale and batch operation. The interference of the operational parameters of exposure time (s) to the radiation and the level of liquid blade $(\mathrm{cm})$ of the effluent in the UV reactor were analyzed. The efficiency of the disinfection process was checked using the indicators microorganisms Clostridium perfringens (C. perfringens), coliphages, Escherichia coli(E. coli) and total coliforms (TC). After disinfection, some tests were carried out to evaluate the phenomena of microbiological recovery: photoreactivation and dark repair, for $E$. coli and TC. The results indicate effective inactivation of indicator microorganisms by UV radiation during the time of exposure, which was statistically proved by repeated measures ANOVA. C. perfringens was the microorganism that showed the highest resistance against UV inactivation. In microbiological recovery tests, both mechanisms were considered insignificant, which was statistically proven by the Student (t test - parametric data) and the Wilcoxon (nonparametric data) tests. In all analyses, the level of significance was $5 \%$.
\end{abstract}

Keywords: disinfection; ultraviolet radiation; indicators microorganisms; mechanisms of microbiological recovery.

\section{INTRODUÇÃO}

A desinfecção de esgotos é uma barreira sanitária indispensável quando se pretende aproveitar o potencial de multiplicidade de uso das águas sem causar danos ou riscos à saúde da população, especialmente quando se faz o uso expressivo dos recursos hídricos para a diluição de despejos e levando-se em consideração o contexto atual de urgente consolidação das práticas de reúso de esgotos sanitários.

As doenças de transmissão hídrica provocadas por águas contaminadas com esgoto sanitário matam cerca de 2,1 milhões de pessoas por ano em todo o mundo (PRÜSS et al., 2002) e, de acordo com Bain et al. (2014), 1,8 bilhão de pessoas em todo o planeta usam fontes de

'Universidade Estadual do Centro-Oeste do Paraná - Itati (PR), Brasil.

*Autor correspondente: raphaelp6@hotmail.com

Recebido: 30/O5/2016 - Aceito: O4/O7/2017 - Reg. ABES: 164557 
água infectadas por microrganismos fecais para fins de abastecimento, sendo que destas, 1,1 bilhão consomem água com grau de risco moderado (>10 unidades formadoras de colônias - UFC. $100 \mathrm{~mL}^{-1}$ E. coli ou coliforme termotolerante) e $10 \%$ consomem águas consideradas de alto risco (>100 UFC. $100 \mathrm{~mL}^{-1}$ E. coli ou coliforme termotolerante).

Tradicionalmente, a qualidade microbiológica das águas é avaliada pelo monitoramento de bactérias não patogênicas, incluindo coliformes totais (CT) e Escherichia coli (E. coli), sendo o último um indicador específico de contaminação fecal. Entretanto, outros indicadores considerados alternativos aos coliformes termotolerantes vêm sendo investigados como potenciais parâmetros substitutos ou complementares, como os colifagos, que podem informar sobre a eficiência do tratamento de água na remoção de enterovírus, e outros vírus como os das hepatites A e E, que são de veiculação hídrica, e Clostridium perfringens (C. perfringens), que, por ser esporulado, informa sobre poluição fecal mais remota que aquelas indicadas pela presença de E. coli. De acordo com Payment e Franco (1993) e Hijnen et al. (1997), esses microrganismos têm sido sugeridos como parâmetros indicadores para avaliar a capacidade dos processos de tratamento de água para remover (oo) cistos de protozoários e vírus patogênicos.

A radiação UV atua como um processo físico de desinfecção em que a inativação microbiana ocorre quando a radiação emitida por lâmpadas especiais, de vapor de mercúrio (baixa ou média pressão), no comprimento de onda de aproximadamente $254 \mathrm{~nm}$, atinge o material genético (DNA e RNA) dos organismos-alvo e as reações fotoquímicas incapacitam a reprodução celular, a partir de alterações das funções enzimáticas dos microrganismos (USEPA, 1999a; HALLMICH \& GEHR, 2010; JUNGFER; SCHWARTZ; OBST, 2007; RODRIGUEZ et al., 2014).

O uso da radiação ultravioleta (UV) como alternativa ao cloro para a desinfecção de esgoto sanitário se destaca devido aos impactos negativos associados ao lançamento de efluentes clorados nos corpos receptores, bem como às vantagens associadas ao uso dessa tecnologia como a não geração de subprodutos potencialmente carcinogênicos, o menor requisito de área para instalação das unidades, a facilidade de operação e a boa eficácia na inativação de bactérias, protozoários e vírus (USEPA, 1999b; HALLMICH \& GEHR, 2010; HIJNEN; BEERENDONK; MEDEMA, 2006).

Salienta-se que, no Brasil, essa tecnologia ainda é pouco utilizada no tratamento de efluentes, fato provavelmente atribuído à baixa qualidade dos rejeitos produzidos nas estações de tratamento em relação aos parâmetros turbidez e presença de sólidos, além de informações imprecisas na literatura nacional sobre os custos associados à instalação e à operação das unidades UV, apesar de Metcalf e Eddy (2003) abordarem a viabilidade econômica do uso dessa radiação em comparação ao cloro para a desinfecção de efluentes, especialmente quando se considera a necessidade de descloração posterior dos resíduos antes do seu lançamento em corpos d’água.
Uma potencial desvantagem do emprego da radiação UV é a possibilidade de ocorrência dos mecanismos de recuperação do dano sofrido pelos microrganismos irradiados, dos quais os principais são a fotorreativação, quando a recuperação ocorre na presença de luz, e a recuperação no escuro, quando o fenômeno ocorre sem a dependência da luz (USEPA, 1999a). Tais fenômenos podem comprometer sobremaneira a eficácia da desinfecção UV ou mesmo inviabilizar o uso dessa tecnologia, uma vez que as concentrações remanescentes dos microrganismos-alvos podem aumentar novamente, representando, assim, um obstáculo para se alcançarem níveis confiáveis de desinfecção (HALLMICH \& GEHR, 2010).

A presente pesquisa visou ao estudo, em escala de laboratório, do processo de desinfecção por radiação UV empregando-se os microrganismos indicadores E. coli, CT, colifagos e C. perfringens, bem como a avaliação dos fenômenos de fotorreativação e recuperação no escuro para os microrganismos indicadores CT e E. coli.

\section{MATERIAIS E MÉTODOS}

\section{Esgoto sanitário: caracterização físico-química e microbiológica}

O efluente usado na pesquisa foi proveniente de uma Estação de Tratamento de Esgoto (ETE) municipal composta de reator tipo anaeróbio de fluxo ascendente e manta de lodo (upflow anaerobic sludge blanket - UASB) seguido de filtro anaeróbio, sendo as amostras coletadas na saída desse sistema.

A caracterização físico-química do efluente foi realizada de acordo com o preconizado no Standard Methods for the Examination of Water and Wastewater (APHA; AWWA; WEF, 1999), tendo sido analisados os parâmetros turbidez, sólidos totais (ST), sólidos suspensos totais (SST) e absorbância medida em comprimento de onda de $254 \mathrm{~nm}$ (cálculo da dose média efetiva).

Para a verificação da qualidade microbiológica inicial do efluente e da eficiência de desinfecção, foram empregados os microrganismos indicadores: E. coli, CT, C. perfringens e colifagos.

Para a determinação de E. coli e CT, foi usada a técnica de filtração em membranas (Method 9222, APHA; AWWA; WEF, 1999) com o emprego de membranas de nitrato de celulose de $0,45 \mu \mathrm{m}$ (Sartorius, AG, Goettingen, Germany) e o meio de cultura Agar Hicrome Seletivo ECC Base Agar CAT.M1294 (Himedia). Para C. perfringens, foi empregada a técnica de tubos múltiplos segundo a Norma L5.213 (CETESB, 1993), empregando os meios de cultura (ambos da Himedia): Differential Reinforced Clostridial (DRCM) M549 no exame presuntivo e o Litmus Milk M609 no confirmativo. Para colifagos, empregou-se o ensaio de placa segundo a Norma L5.225 (CETESB, 1990), com o meio de cultura Tryptic Soy Agar (TSA) M290 (Himedia), e foi usado também o meio 
Tryptic Soy Broth (TSB) M011 (Himedia) para crescimento e manutenção das células hospedeiras de E. coli, as cepas CIP 055, adquiridas da Fundação Tropical de Pesquisas e Tecnologia André Tosello, em Campinas (SP).

\section{O reator UV e a medição da intensidade de radiação}

O reator UV foi confeccionado em aço inox, com cúpula removível em alumínio com $10 \mathrm{~cm}$ de altura e dimensões da caixa de $40 \times 45 \times$ $15 \mathrm{~cm}$ e 6 lâmpadas emersas de baixa pressão de vapor de mercúrio da marca Philips ${ }^{\oplus}$, distanciadas entre si em $2,2 \mathrm{~cm}$, com $15 \mathrm{~W}$ de potência nominal cada uma e interruptores individuais de energia.

Para a determinação da intensidade de radiação emitida pelas lâmpadas UV, foi empregado um radiômetro da marca Vilber Loumart ${ }^{\circledR}$ (VLX-3W), com sensor que detecta a radiação UV no comprimento de onda de $254 \mathrm{~nm}$.

Para a obtenção da intensidade média de radiação, foi adotada uma malha de pontos equidistantes em $5 \mathrm{~cm}$, totalizando $56 \mathrm{e}$, a partir das medições em cada um desses pontos, obteve-se a intensidade média de radiação UV emitida pela fonte $\left(\mathrm{I}_{0}\right)$. A intensidade média efetiva (Im) (Equação 1) foi calculada de acordo com a Lei de Beer-Lambert (Equação 2), que leva em consideração o coeficiente de absorção (atenuação) e a espessura da lâmina líquida:

$\operatorname{Im}={ }_{0}^{\mathrm{I}}{ }_{\mathrm{a}^{*} \mathrm{~L}}{ }^{*}\left[1-\mathrm{e}^{\left(-\mathrm{a}^{*} \mathrm{~L}\right)}\right]$

Em que:

Im = intensidade média efetiva $\left(\mathrm{mW} \cdot \mathrm{cm}^{-2}\right)$;

$\mathrm{I}_{0}=$ intensidade média da radiação emitida pela fonte e aplicada à superfície $\left(\mathrm{mW} . \mathrm{cm}^{-2}\right)$;

$\alpha=$ coeficiente de absorção $\left(\mathrm{cm}^{-1}\right)$;

$\mathrm{L}=$ espessura da lâmina líquida $(\mathrm{cm})$.

$\alpha=\mathrm{A}^{\star} \ln (10)=2,303^{\star} \mathrm{A}$

Em que:

$\alpha=$ coeficiente de absorbância $\left(\mathrm{cm}^{-1}\right)$;

$\mathrm{A}=$ absorbância medida a $254 \mathrm{~nm}\left(\mathrm{~cm}^{-1}\right)$.

Para a determinação da dose média efetiva, foi empregada a Equação 3:

$\mathrm{Dm}=\operatorname{Im}^{\star} t$

Em que:

$\mathrm{Dm}=$ dose média efetiva $\left(\mathrm{mWs} . \mathrm{cm}^{-2}\right) ;$

$\mathrm{I}=$ intensidade média de radiação $\left(\mathrm{mWs} . \mathrm{cm}^{-2}\right)$;

$\mathrm{T}=$ tempo de exposição (s).
A eficiência de inativação microbiana foi calculada pela Equação 4

Eficiência $(\log )=\log _{10}\left(\mathrm{~N} / \mathrm{N}_{0}\right)$

Em que:

$\mathrm{N}_{0}$ = número inicial de microrganismos;

$\mathrm{N}$ = número de microrganismos remanescentes após desinfecção por radiação UV.

\section{Ensaios de desinfecção}

Previamente aos ensaios de desinfecção, as lâmpadas do reator UV eram ligadas por um período de 15 minutos, para aquecimento e estabilização. Os ensaios de desinfecção foram realizados utilizando-se as 6 lâmpadas ligadas, com tempos de exposição de 15, 30 e 45 segundos para espessura de lâmina líquida de $2 \mathrm{~cm}$ (ensaio ALL2) e $4 \mathrm{~cm}$ (ensaio ALL4) e tempos de exposição de 30, 60 e 90 segundos para a espessura da lâmina líquida de $6 \mathrm{~cm}$ (ensaio ALL6). Após cada tempo de exposição, alíquotas do efluente eram coletadas para a realização dos exames microbiológicos e obtenção do número final de microrganismos $(\mathrm{N})$.

Para que fosse possível variar a altura da lâmina líquida e manter constante a altura da lâmpada até a superfície do efluente, foram empregados dois adaptadores em aço inox medindo $40 \times 45 \mathrm{~cm}$ e alturas de 2 e $4 \mathrm{~cm}$. Para o ensaio ALL2, não houve necessidade de utilizar o adaptador; para os demais, foram utilizados os de $2 \mathrm{~cm}$ (ensaio ALL4) e $4 \mathrm{~cm}$ (ensaio ALL6). Vale ressaltar que o efluente era mantido em agitação constante (homogeneização); para cada altura de lâmina líquida, foram realizadas três campanhas amostrais e, em todos os ensaios, a altura entre a lâmpada e a superfície do efluente foi de $14 \mathrm{~cm}$.

\section{Ensaios de recuperação microbiológica}

Nos ensaios de recuperação microbiológica (E. coli e CT), seguiu-se a metodologia também realizada por Tinôco (2011): para o ensaio de fotorreativação, alíquotas de $100 \mathrm{~mL}$ foram expostas à radiação solar por um período de 3 horas, em béquer de $250 \mathrm{~mL}$, parcialmente tampado com vidro de relógio e coberto com policloreto de vinila (PVC), o qual foi perfurado para a passagem de ar. Para o ensaio de recuperação no escuro, alíquotas de mesma quantidade foram acondicionadas em frascos plásticos e mantidas em ambiente escuro por um período de três horas. Os horários da realização dos ensaios de recuperação microbiológica foram das 11 às $14 \mathrm{~h}$.

A temperatura do ensaio ALL2 foi, em média, de $17 \pm 1,0^{\circ} \mathrm{C}$ e o céu estava parcialmente nublado em todos os experimentos. Já para o ALL4, a temperatura foi de $27,7 \pm 5,0^{\circ} \mathrm{C}$ e o céu estava com poucas nuvens para todos os ensaios. No ALL6, a temperatura média foi de $21,6 \pm 7,8^{\circ} \mathrm{C} \mathrm{e}$, em uma das triplicatas, o tempo estava chuvoso e nublado, e no restante, parcialmente nublado. A temperatura nos ensaios de recuperação no escuro foi de $25^{\circ} \mathrm{C}$ em todos os ensaios. 


\section{Análises estatísticas}

Visando observar a correlação entre absorbância e concentração de SST e turbidez, foi aplicada a correlação de Kendall. Já para avaliar se o tempo de exposição à radiação UV (doses médias efetivas) era um fator significativo na inativação dos microrganismos indicadores empregados, foram calculadas as análises de variâncias de medidas repetidas com um fator (tempo de exposição). Ambos utilizando o software STATISTICA 7.0 ${ }^{\circledR}$.

Quando as amostras não apresentavam esfericidade, o teste de GreenhouseGeisser foi utilizado para corrigir os graus de liberdade e o valor de teste $\mathrm{F}$ para amostras dependentes. Concomitantemente os coeficientes de variação foram calculados para auxiliar na interpretação dos resultados.

Nos ensaios de recuperação microbiológica (fotorreativação e recuperação no escuro), foram aplicados os testes $t$ de Student e o de Wilcoxon para amostras dependentes, com o objetivo de analisar se as médias da concentração remanescente dos microrganismos indicadores após a desinfecção por radiação UV difeririam ou não estatisticamente das médias da concentração após os ensaios de recuperação microbiológica (o teste $t$, neste caso, torna-se a análise mais apropriada). O teste de hipótese de Wilcoxon substitui o $t$ (amostras pareadas) quando os dados não são paramétricos. Vale ressaltar que para todas as análises estatísticas o nível de significância foi de $5 \%(\mathrm{p}<0,05)$.

\section{RESULTADOS E DISCUSSÃO}

Na Tabela 1, são apresentados os resultados das intensidades e doses médias efetivas de radiação UV para cada ensaio.

A intensidade média dessa radiação foi de 5,48 $\pm 1,09$. Levando em consideração a atenuação ocasionada pela absorção da radiação UV no meio líquido (lei de Beer-Lambert), a altura de lâmina líquida, a absorbância (254 nm) e o tempo de exposição, foram calculadas as intensidades médias efetivas (Im) e as doses médias efetivas.

Na Tabela 2, são apresentados os resultados da caracterização físico-química e microbiológica do efluente para os ensaios ALL2, ALL4 e ALL6.

A absorbância, a turbidez e os SST interferiram na eficiência da desinfecção por radiação UV. A absorbância está associada à concentração de sólidos suspensos, metais e componentes orgânicos e inorgânicos também dissolvidos presentes na água ou no esgoto (METCALF E EDDY, 2003). A turbidez está relacionada à concentração de SST e, em ambos os casos, as partículas servem de proteção aos microrganismos-alvo e absorvem parcela dessa radiação (BURCH \& THOMAS, 1998; TEMPLETON; HOFMANN; ANDREWS, 2006).

Os valores de absorbância possuem correlação com a concentração de SST $\left(\mathrm{r}_{\text {Kendall }}=0,50 ; \mathrm{p}<0,05\right)$ e turbidez $\left(\mathrm{r}_{\text {Kendall }}=0,50 ; \mathrm{p}<0,05\right)$. Nesse

Tabela 1 - Resultados das intensidades e doses médias efetivas de radiação ultravioleta.

\begin{tabular}{|c|c|c|c|c|c|c|}
\hline $\begin{array}{l}\text { Intensidade média de radiação } \\
\text { na superfície }\left(\mathrm{I}_{0}\right)\left(\mathrm{mW} \cdot \mathrm{cm}^{-2}\right)\end{array}$ & $\begin{array}{l}\text { Espessura da lâmina } \\
\text { líquida }(\mathrm{cm})\end{array}$ & Ensaio & $\begin{array}{l}\text { Absorbância } \\
\text { (254 nm) }\end{array}$ & $\begin{array}{c}\text { Tempo de } \\
\text { exposição (s) }\end{array}$ & $\begin{array}{l}\text { Intensidade média } \\
\text { efetiva }(\mathrm{Im})\left(\mathrm{mW} \cdot \mathrm{cm}^{-2}\right)\end{array}$ & $\begin{array}{l}\text { Dose média efetiva } \\
\left(\mathrm{mWs} . \mathrm{cm}^{-2}\right)\end{array}$ \\
\hline \multirow{9}{*}{$5,48 \pm 1,09$} & \multirow{3}{*}{2} & \multirow{3}{*}{ ALL2 } & \multirow{3}{*}{$0,45 \pm 0,2$} & 15 & $2,29 \pm 0,7$ & $34,47 \pm 11,2$ \\
\hline & & & & 30 & $2,29 \pm 0,6$ & $68,07 \pm 19,6$ \\
\hline & & & & 45 & $2,32 \pm 0,7$ & $104,89 \pm 33,6$ \\
\hline & \multirow{3}{*}{4} & \multirow{3}{*}{ ALL4 } & \multirow{3}{*}{$0,59 \pm 0,2$} & 15 & $1,04 \pm 0,2$ & $15,12 \pm 3,8$ \\
\hline & & & & 30 & $1,02 \pm 0,2$ & $30,48 \pm 8,2$ \\
\hline & & & & 45 & $1,06 \pm 0,2$ & $47,58 \pm 11,5$ \\
\hline & \multirow{3}{*}{6} & \multirow{3}{*}{ ALL6 } & \multirow{3}{*}{$0,47 \pm 0,3$} & 30 & $1,04 \pm 0,5$ & $31,22 \pm 16,2$ \\
\hline & & & & 60 & $1,11 \pm 0,5$ & $66,35 \pm 34,1$ \\
\hline & & & & 90 & $1,10 \pm 0,5$ & $98,68 \pm 48,6$ \\
\hline
\end{tabular}

Tabela 2 - Caracterização físico-química e microbiológica do efluente.

\begin{tabular}{|c|c|c|c|}
\hline Parâmetros & Ensaio ALL2 & Ensaio ALL4 & Ensaio ALL6 \\
\hline Turbidez (uT) & $45,33 \pm 16,56$ & $54,13 \pm 22,83$ & $33,73 \pm 11,83$ \\
\hline Temperatura (OC) & $17,00 \pm 1,00$ & $19,33 \pm 1,53$ & $20,00 \pm 3,46$ \\
\hline $\mathrm{pH}$ & $7,08 \pm 0,35$ & $7,42 \pm 0,35$ & $7,06 \pm 0,19$ \\
\hline Sólidos totais (mg ST.L-1) & $191,00 \pm 127,08$ & $397,67 \pm 80,00$ & $239,33 \pm 182,32$ \\
\hline Sólidos suspensos totais (mg SST.L-1) & $8,67 \pm 2,52$ & $17,33 \pm 4,04$ & $17,00 \pm 6,56$ \\
\hline Absorbância (254 nm) & $0,45 \pm 0,19$ & $0,59 \pm 0,19$ & $0,47 \pm 0,31$ \\
\hline Escherichia coli (UFC.100 $\left.\mathrm{mL}^{-1}\right)^{*}$ & $4,79 \pm 0,20$ & $5,57 \pm 0,35$ & $4,47 \pm 1,46$ \\
\hline Coliformes totais (UFC.100 mL-1)* & $6,09 \pm 0,65$ & $5,65 \pm 0,44$ & $5,25 \pm 0,71$ \\
\hline Clostridium perfringens (NMP.100 $\left.\mathrm{mL}^{-1}\right)^{*}$ & $6,21 \pm 0,90$ & $5,87 \pm 0,58$ & $5,87 \pm 0,58$ \\
\hline Colifagos (UFP.100 mL-1)* & $3,65 \pm 0,07$ & $2,60 \pm 0,22$ & $3,08 \pm 0,82$ \\
\hline
\end{tabular}

*Os valores dos parâmetros microbiológicos Escherichia coli, coliformes totais, Clostridium perfringens e colifagos foram convertidas em unidades logarítmicas. 
contexto, maiores valores de absorbância implicam maiores valores tanto de SST quanto de turbidez, podendo contribuir com menores valores de dose de radiação e na eficiência da desinfecção.

Ocorreu aumento na concentração de SST, porém esses valores ficaram abaixo de 30 mg.L.-1, que é o recomendado pela USEPA (1999b).

\section{Ensaios de desinfecção}

Nas Figuras 1, 2 e 3, são apresentados os resultados das eficiências, em $\log \mathrm{N} / \mathrm{N}_{0}$, dos ensaios de desinfecção com radiação UV.

No ensaio ALL2 (Figura 1), com base na análise de variância de medidas repetidas (5\%), observou-se decréscimo significativo para os microrganismos indicadores E. coli $(\mathrm{F}=14,46 ; \mathrm{p}=0,01), \mathrm{CT}(\mathrm{F}=5,58$; $\mathrm{p}=0,01)$ e colifagos $(\mathrm{F}=107,95 ; \mathrm{p}=0,01)$ com o aumento do tempo de exposição e das doses de radiação UV empregadas, enquanto C. perfringens foi o microrganismo que apresentou maior resistência, pois não ocorreram diferenças significativas entre as médias no decorrer do aumento do tempo de exposição $(\mathrm{F}=0,49 ; \mathrm{p}=0,60)$. Vale ressaltar que os coeficientes de variação para este ensaio foram menores que $20 \%$, indicando precisão nos resultados.

No ensaio ALL4 (Figura 2), de modo geral, observou-se sensibilidade dos microrganismos à radiação UV no decorrer do tempo de exposição, por causa do aumento de suas doses: $\operatorname{E} \cdot \operatorname{coli}(\mathrm{F}=5,97 ; \mathrm{p}=0,03)$ e colifagos $(F=8,66 ; p=0,01)$. Observou-se o decaimento delas em comparação ao ensaio anterior, pois, nesse ensaio, ocorreu queda na qualidade físico-química do efluente. A análise de variância de medidas repetidas não indicou decréscimo estatisticamente significativo na concentração remanescente de $C$. perfringens com o aumento do tempo de exposição $(\mathrm{F}=1,24 ; \mathrm{p}=0,38)$ e $\mathrm{CT}(\mathrm{F}=2,00 ; \mathrm{p}=0,28)$.

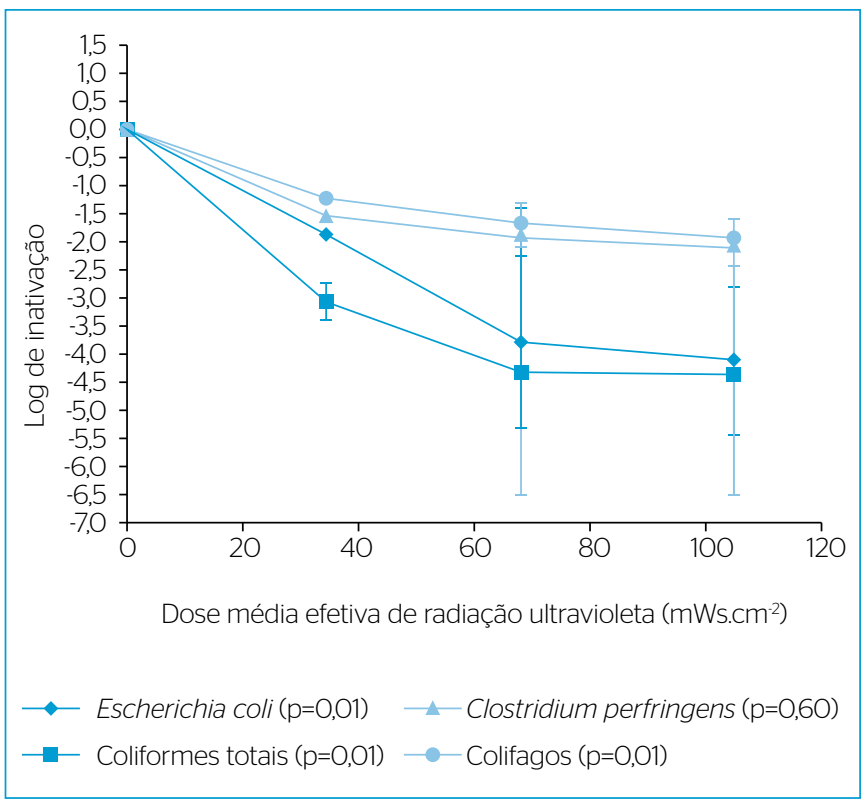

Figura 1 - Eficiência (log) de desinfecção por radiação ultravioleta para o ensaio ALL2.
Em relação ao grupo CT, os resultados das eficiências das triplicatas, após 45 segundos de exposição à radiação UV, oscilaram de 0,20 a 5,97 log de inativação. O coeficiente de variação para esse microrganismo indicador foi de $46 \%$, portanto elevado. Essa variação foi determinante no resultado da análise de variância de medidas repetidas que não representou diferença estatística para esse tempo de exposição, enquanto os demais coeficientes de variação foram abaixo de $20 \%$.

No ensaio ALL6 (Figura 3), de acordo com a análise de variância de medidas repetidas, observou-se decréscimo significativo para os

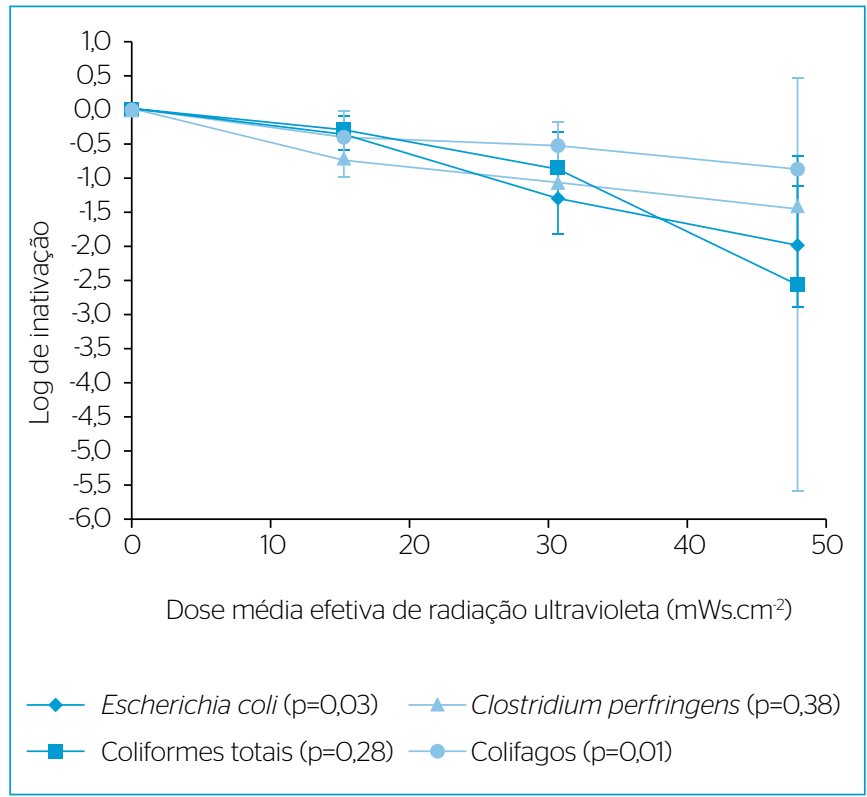

Figura 2 - Eficiência (log) de desinfecção por radiação ultravioleta para o ensaio ALL4.

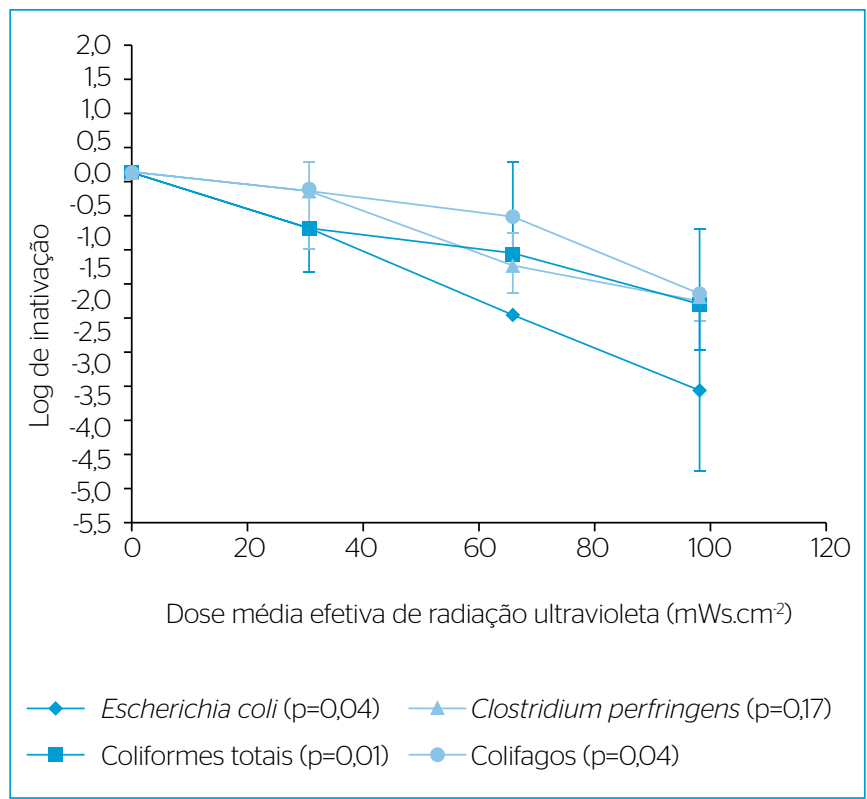

Figura 3 - Eficiência (log) de desinfecção por radiação ultravioleta (UV) para o ensaio ALL6. 
microrganismos indicadores $E$. coli $(\mathrm{F}=7,45 ; \mathrm{p}=0,04), \mathrm{CT}(\mathrm{F}=40,43$; $\mathrm{p}=0,01)$ e colifagos $(\mathrm{F}=9,14 ; \mathrm{p}=0,04)$ no decorrer do tempo de exposição. Para o microrganismo C. perfringens $(\mathrm{F}=3,75 ; \mathrm{p}=0,17)$, não ocorreu diferença entre as médias. Para todos os microrganismos indicadores, o coeficiente de variação foi menor que $20 \%$, indicando boa precisão dos dados.

Com base nos resultados, pode-se observar que a resistência à desinfecção por radiação UV foi classificada na seguinte ordem: bactérias< <írus< <esporos, o que também foi observado por Burch e Thomas (1998).

$\mathrm{Na}$ Figura 4, é apresentada a eficiência (\%) de inativação microbiana de todos os microrganismos estudados em função das alturas de lâmina líquida para o tempo de exposição de 30 segundos (tempo em comum de todos os ensaios).

Observou-se que, mantendo o tempo de exposição de 30 segundos e aumentando a altura de lâmina líquida, as eficiências de inativação microbiana diminuíram. C. perfringens foi o microrganismo que apresentou maior resistência, por tratar-se de uma bactéria formadora de esporos que, de fato, é resistente à desinfecção (HIJNEN; BEERENDONK; MEDEMA, 2006).

\section{Ensaios de recuperação microbiológica}

Nas Figuras 5, 6 e 7, são apresentados, respectivamente, os resultados referentes aos ensaios de recuperação microbiológica no que tange aos microrganismos indicadores E. coli e CT para as três alturas de lâmina líquida (ALL2, ALL4 e ALL6), além dos resultados dos testes $t$ (paramétrico) e de Wilcoxon (não paramétricos) para amostras dependentes em cada tempo de exposição.

Todos os resultados do teste Wilcoxon foram $\mathrm{p}<0,01$ em um nível de significância de 5\%, sendo que, nas Figuras 5, 6 e 7, F significa

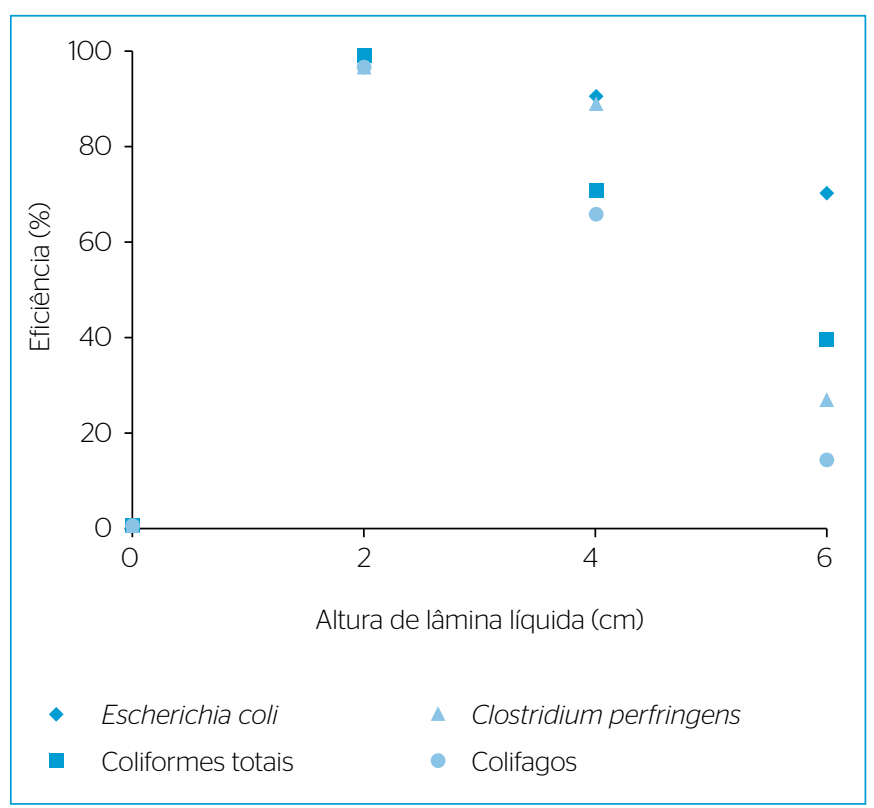

Figura 4 - Eficiência de inativação (\%) para o tempo de exposição de 30 segundos. fotorreativação e RE, recuperação no escuro. Valores que permanecem no 0 indicam que a concentração remanescente após a desinfecção por UV permaneceu a mesma, os acima de 0 apontam recuperação e os abaixo, desinfecção, em $\log \mathrm{N} / \mathrm{N}_{0}$.

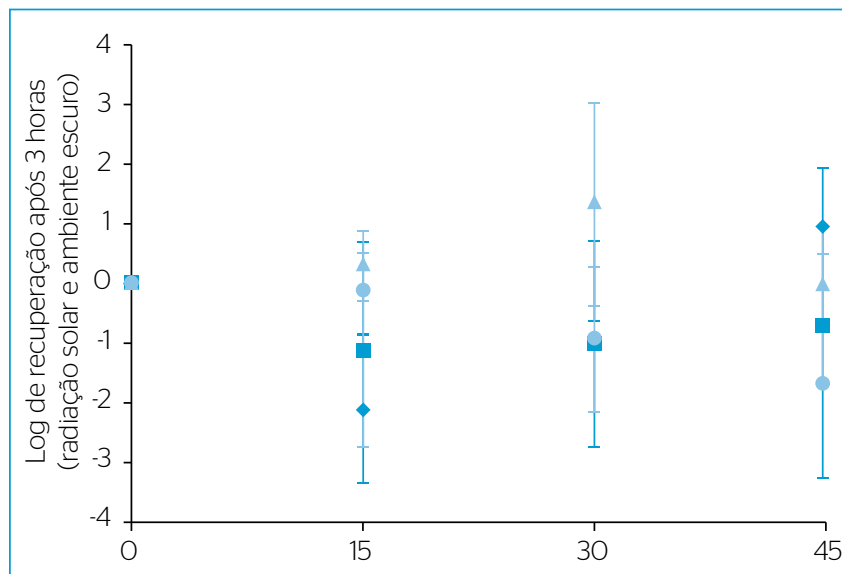

Alíquotas dos tempos de exposição ultravioleta (segundos)

$$
\begin{aligned}
& \text { - Escherichia coli } \mathrm{F} \text { ( } \mathrm{p} 15=0,01^{*} \text {; } \mathrm{p} 30<0,01^{\star} ; \mathrm{p} 45=0,34 \text { ) } \\
& \text { - Escherichia coli RE (p15=0,07; p30<0,01*; } 445<0,01^{*} \text { ) } \\
& \Delta \text { Coliformes totais F (p15=0,38; p30=0,12; p45=0,88) } \\
& \text { - Coliformes totais RE ( } 15=0,60 ; p 30=0,40 ; p 45<0,01^{*} \text { ) }
\end{aligned}
$$

Figura 5 - Resultados da recuperação média nos ensaios de fotorreativação e recuperação no escuro para o ensaio ALL2.

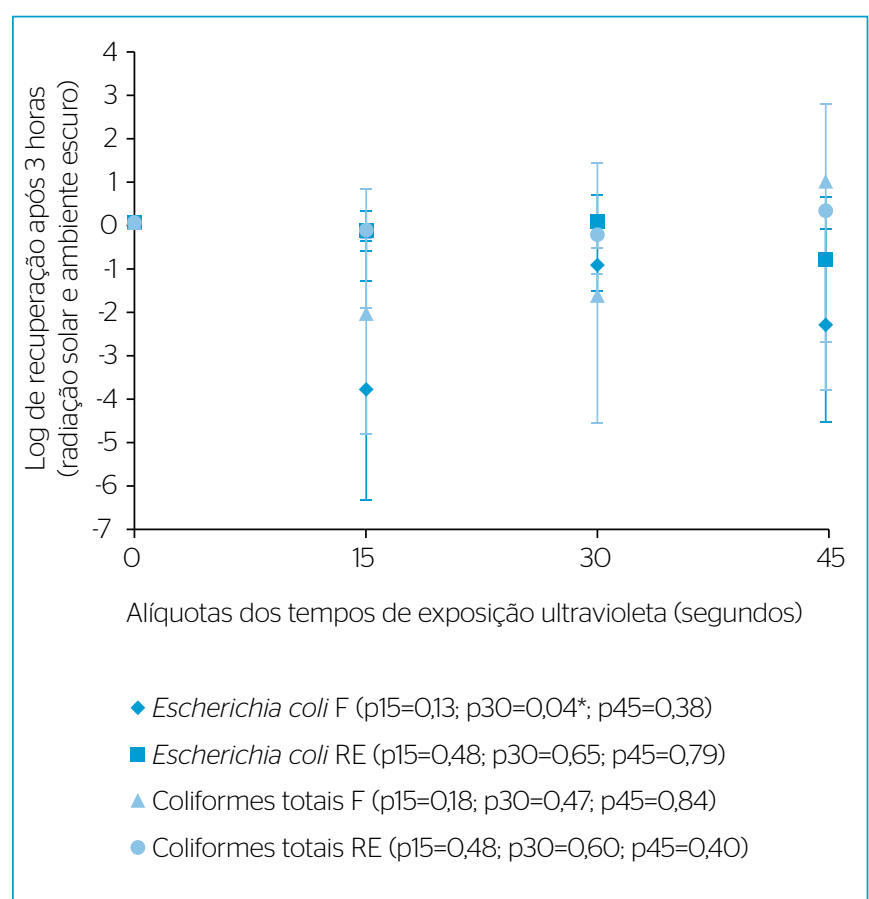

Figura 6 - Resultados da recuperação média nos ensaios de fotorreativação e recuperação no escuro para o ensaio ALL4. 
No ensaio ALL2, observou-se a fotorreativação para ambos os microrganismos indicadores. Entretanto, os mecanismos de recuperação microbiológica foram considerados insignificantes, sendo comprovado estatisticamente pelos testes $t$ e Wilcoxon.

Nos ensaios de fotorreativação de ALL2, o teste $t$ e o de Wilcoxon indicaram diferença entre as médias da concentração remanescente para $E$. coli, porém essa diferença não está relacionada com a parcela que foi recuperada. Pelo teste $t$, detectou-se diferença entre as médias na alíquota coletada após 15 segundos de exposição à radiação UV $(\mathrm{p}=0,01)$, na qual se observou redu-

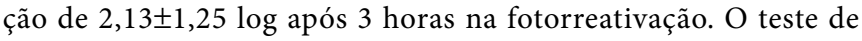
Wilcoxon (não paramétrico) indicou diferença significativa para a alíquota exposta na fotorreativação do tempo de 30 segundos $(\mathrm{p}<0,01)$, em que se notou inativação de $100 \%$, ou seja, inativação

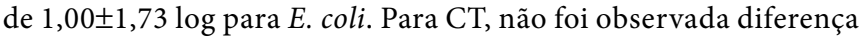
entre as médias da concentração remanescente após a desinfecção e a concentração após a fotorreativação.

Para os ensaios de recuperação no escuro, foi indicada diferença entre as médias no teste de Wilcoxon para as alíquotas coletadas após os tempos de exposição de 30 e 45 segundos $(\mathrm{p}<0,01)$ para E. coli, em que se observou inativação de $100 \%$, ou seja,

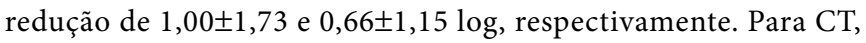
o teste de Wilcoxon detectou diferença na alíquota coletada após 45 segundos de exposição à radiação UV $(\mathrm{p}<0,01)$, com inativação de $100 \%(1,72 \pm 1,54 \log )$.

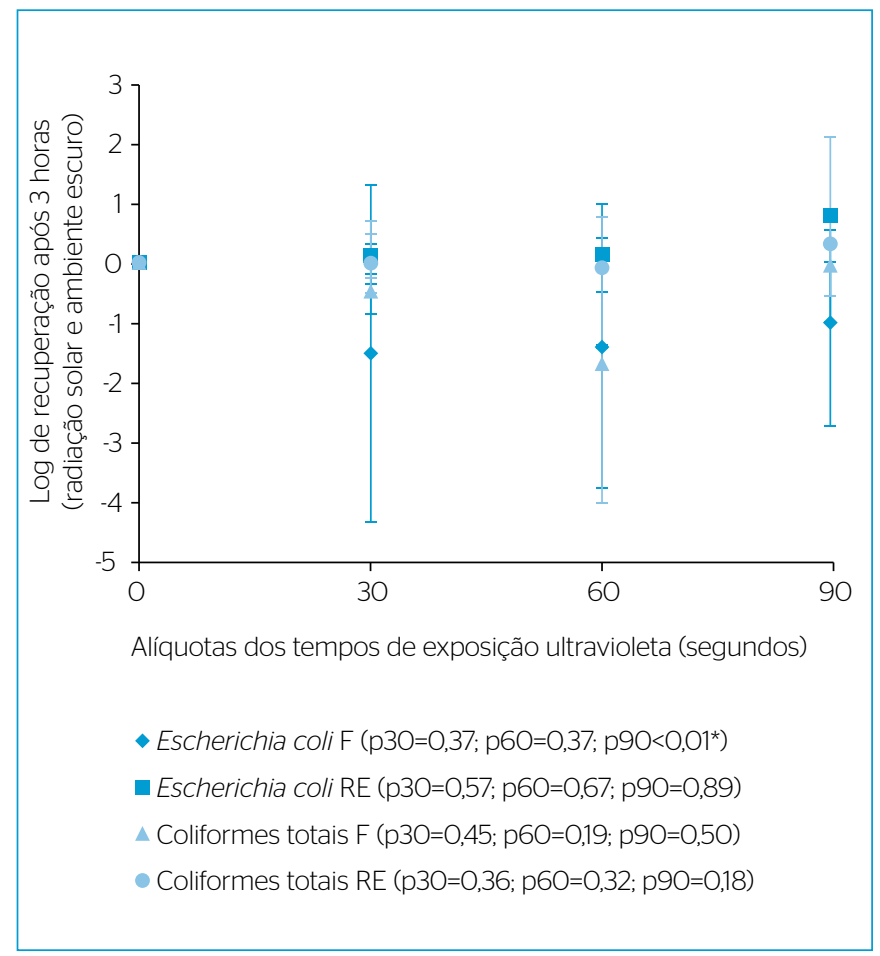

Figura 7 - Resultados da recuperação média nos ensaios de fotorreativação e recuperação no escuro para o ensaio ALL6.
As médias das concentrações remanescentes dos microrganismos indicadores para as amostras coletadas nesses tempos, após a desinfecção, diminuíram significativamente após três horas de exposição à radiação solar e em ambiente escuro, indicando que a desinfecção prevaleceu aos processos de recuperação.

Para a fotorreativação, no caso do ensaio ALL4, o teste $t$ indicou diferença entre as médias da concentração remanescente de $E$. coli após 30 segundos $(\mathrm{p}=0,04)$. Entretanto, o efeito da desinfecção prevaleceu à fotorreativação, mostrando uma redução média de $0,97 \pm 0,62 \log$. A recuperação no escuro para CT e E. coli foi considerada insignificante. $\mathrm{O}$ teste $t$ não detectou diferença entre as médias para ambos os microrganismos.

No ensaio ALL6, para a fotorreativação, o teste de Wilcoxon indicou diferença significativa entre as médias para a alíquota coletada após 90 segundos $(\mathrm{p}<0,01)$ para E. coli. Observou-se inativação de $100 \%$ $(1,00 \pm 1,73 \mathrm{log})$. Os ensaios de recuperação no escuro foram considerados insignificantes nesse caso.

O decréscimo da concentração remanescente dos microrganismos estudados (comprovado estatisticamente) após a desinfecção por radiação UV pode estar relacionado também com o efeito da ação germicida da luz solar. Os horários empregados para o estudo da possibilidade dos mecanismos de reparos estão dentro da faixa ótima para a desinfecção por radiação solar (das 09h às 15h), pois a radiação é máxima no horário das $12 \mathrm{~h}$ às $13 \mathrm{~h}$.

Pode-se, com base nos resultados, observar que a fotorreativação, mesmo insignificante estatisticamente neste estudo, foi mais perceptível para as menores doses médias efetivas de radiação UV (GUO et al., 2011; LINDENAUER \& DARBY, 1994).

\section{CONCLUSÃO}

A absorbância UV $254 \mathrm{~nm}$ correlaciona-se com a concentração de SST e turbidez, sendo que esses parâmetros são limitantes à desinfecção por radiação UV. Absorbâncias maiores implicam doses médias efetivas menores.

Os resultados demonstraram eficiências satisfatórias de inativação dos microrganismos E. coli, CT e colifagos, o que foi comprovado significativamente pela análise de variância de medidas repetidas (5\%), tendo como fator o tempo de exposição (aumento das doses médias efetivas de radiação).

C. perfringens foi o microrganismo indicador que apresentou maior resistência à desinfecção por radiação UV; as médias das concentrações remanescentes desse microrganismo não diferiram para os tempos de exposição empregados.

Mantendo o tempo de exposição e aumentando a altura de lâmina líquida, as doses e as eficiências de inativação dos microrganismos indicadores empregados diminuíram. 
Os mecanismos de recuperação microbiológica foram considerados insignificantes nas condições testadas (mostrando que o efeito da desinfecção prevaleceu), o que foi comprovado estatisticamente pelo teste $t$ e pelo de Wilcoxon, em um nível de significância de $5 \%$.

\section{AGRADECIMENTOS}

O presente trabalho foi realizado com o apoio da Coordenação de Aperfeiçoamento de Pessoal de Nível Superior (CAPES) - Código de Financiamento 001.

\section{REFERÊNCIAS}

AMERICAN PUBLIC HEALTH ASSOCIATION (APHA); AMERICAN WATER WORKS ASSOCIATION (AWWA); WATER ENVIRONMENT FEDERATION (WEF). (1999) Standard methods for the examination of water and wastewater. 20. ed. Washington, D.C.: APHA; AWWA; WEF. 2.670 p.

BAIN, R.; CRONK, R.; HOSSAIN, R.; BONJOUR, S.; ONDA, K.; WRIGHT, J.; YANG, H.; SLAYMAKER; HUNTER, P.; PRÜSS-USTÜN, A.; BARTRAM, J. (2014) Global assessment of exposure to fecal contamination through drinking water based on a systematic review. Tropical Medicine and International Health, v. 19, n. 8, p. 917-927. https://doi.org/10.1111/tmi.12334

BURCH, J.D.; THOMAS, K.E. (1998) Water disinfection for developing countries and potential for solar thermal pasteurization. Solar Energy, v. 64, p. 87-97. http://dx.doi.org/10.1016/S0038092X(98)00036-X

COMPANHIA AMBIENTAL DO ESTADO DE SÃO PAULO (CETESB). (1990) Determinação de colifagos em amostras de água: método de ensaio. L5/225. São Paulo: CETESB. 24 p.

(1993) Clostridium perfringens: determinação em amostras de água pela técnica de tubos múltiplos. Método de ensaio L5/213. São Paulo: CETESB. 25 p.

GUO, M.T.; HUANG, J.J.; HIU, H.; LIU, W.J. (2011) Growth and repair potential of three species of bacteria in reclaimed wastewater after UV disinfection. Biomedical and Environmental Sciences, v. 24, n. 4, p. 400-407. https://doi.org/10.3967/0895-3988.2011.04.011

HALLMICH, C.; GEHR, R. (2010) Effect of pre- and post-UV disinfection conditions on photoreactivation of fecal coliforms in wastewater effluents. Water Research, v. 44, p. 2885-2893. https:// doi.org/10.1016/j.watres.2010.02.003

HIJNEN, W.A.; BEERENDONK, E.F.; MEDEMA, G.J. (2006) Inactivation credit of UV radiation for viruses, bacteria and protozoan (oo) cysts in water: a review. Water Research, v. 40, p. 3-22. https://doi. org/10.1016/j.watres.2005.10.030

HIJNEN, W.A.; VAN DER SPELD, W.M.H.; HOUTEPEN, F.A.P.; VAN DER KOOIJ, D. (1997). Spores of sulphite reducing clostridia: a surrogate parameter for assessing the effects of water treatment processes on protozoan(oo)cysts? In: FRICKER, C.R.; CLANCY, J.R.; ROCHELLY, P.A. (Orgs.). Proceedings of the International Symposium on Waterborne Cryptosporidium. Newport Beach, CA/Denver, CO: AWWA. p. 115-125.
JUNGFER, C:; SCHWARTZ, T.; OBST, U. (2007) UV-induced dark repair mechanisms in bacteria associated with drinking water. Water Research, v. 47, p. 188-196. https://doi.org/10.1016/j. watres.2006.09.001

LINDENAUER, K.G.; DARBY, J.L. (1994) Ultraviolet disinfection of wastewater: Effect of dose on subsequent photoreactivation. Water Research, v. 28, n. 4, p. 805-817. https://doi.org/10.1016/00431354(94)90087-6

METCALF E EDDY, INC. (2003) Wastewater engineering - treatment and reuse. 4. ed. Nova York: McGraw-Hill. 1.819 p.

PAYMENT, P.; FRANCO, E. (1993) Clostridium perfringens and somatic coliphages as indicators of the efficiency of drinking water treatment for viruses and protozoan cysts. Applied and Environmental Microbiology, v. 59, n. 8, p. 2418-2424.

PRÜSS, A.; KAY, D.; FEWTRELL, L.; BARTRAM, J. (2002) Estimating the burden of disease from water, sanitation, and hygiene at a global level. Environmental Health Perspectives, v. 110, n. 5, p. 537-542

RODRIGUEZ, R.A.; BOUNTY, S.; BECK, S.; CHAN, C.; McGUIRE, C:; LINDEN, K.G. (2014) Photoreactivation of bacteriophages after UV disinfection: role of genome structure and impacts of UV source. Water Research, v. 55, p. 143-149. https://doi.org/10.1016/j. watres.2014.01.065

TEMPLETON, M.R.; HOFMANN, R.; ANDREWS, R.C. (2006) UV inactivation of humic-coated bacteriophages MS2 and T4 in water. Journal of Environmental Engineering Science, v. 5, p. 537-543. https://doi.org/10.1139/s06-021

TINÔCO, J.D. (2011) Desinfecção por radiação ultravioleta: estudo do desempenho do processo e avaliação econômica. Tese (Doutorado em Engenharia Hidráulica e Saneamento) - Escola de Engenharia de São Carlos, Universidade de São Paulo, São Carlos.

U.S. ENVONMENTAL PROTECTION AGENCY (USEPA). (1999a) Alternative disinfectants and oxidants guidance manual. (EPA 815R-99014). Washington, D.C.: USEPA. 346 p.

(1999b) Wastewater technology fact sheet - Ultraviolet disinfection. (EPA 832-F-99-064). Washington, D.C.: USEPA. 7 p. 